\title{
Socio-pragmatic Failure of Chinese Non-English Majors in Intercultural Communication
}

\author{
ZHOU Yangmeishan, GAO Wencheng \\ University of Shanghai for Science and Technology, Shanghai, China
}

\begin{abstract}
Chinese non-English majors often make many socio-pragmatic mistakes due to their ignorance of English-Chinese cultural backgrounds and pragmatic customs, which exerts a negative impact on their intercultural communications. This paper studies the social pragmatic failure that non-English majors usually make in requests, compliments, apologies, etc., aiming to explore the causes of social pragmatic failure from the aspects of economic background, thinking mode, negative pragmatic transfer, and so on. In addition, a series of corresponding methods are also suggested to reduce social pragmatic failures for non-English majors, so that they can improve their intercultural communication abilities.
\end{abstract}

Keywords: Chinese non-English majors, socio-pragmatic failure, intercultural communication

\section{Introduction}

With the increasing advancement in communication technology and constant development of economic globalization, English is becoming a common language in the world. People are interacting more with others from around the world. Because of the differences between the Eastern and Western cultures, pragmatic failure often occurs in English-Chinese intercultural communication, which becomes an obstacle for the accuracy and efficiency of communication.

Pragmatic failure can be divided into pragmalinguistic failure and socio-pragmatic failure, and the latter is the major problem in intercultural communication. Elemam (2018) held that without a solid understanding of pragmatics, non-native speakers of English may encounter professional failure in the future. Leech (1983) put forward the Politeness Principle, which serves as a necessity for an effective cross-cultural communication. And Kasper (1992) found that pragmatic transfer could also be an important reason for pragmatic failure.

This paper, based on the theories that the researchers above have set forth, aims to explore the socio-pragmatic failures of non-English majors in China, and it also illustrates some countermeasures to reduce non-English majors' socio-pragmatic failures, which can be beneficial for non-English majors to have an effective communication with English native speakers .

\section{Literature Review}

Language distinguishes human beings from other animals. Human beings do not exist in the world alone.

ZHOU Yangmeishan, Master, College of Foreign Languages, University of Shanghai for Science and Technology, Shanghai, China.

GAO Wencheng, Doctor, Professor, College of Foreign Languages, University of Shanghai for Science and Technology, Shanghai, China. 
Arensberg and Niehoff (1964) believed that nothing can distinguish one culture from another more clearly than its language. Serving as the tool of human minds and the carrier of culture, language is a reflection of culture, and vice versa. Culture exerts influence on language by rules, symbols, and our ideas of the universe. Every aspect of our life is influenced by culture, and language serves as a part of culture. It is obvious that every culture carries the regional and national characteristics, and that is the so-called cultural individuality. Therefore, one must have a better understanding of the target language culture in order to learn a foreign language well and use it effectively in intercultural communication.

Intercultural communication refers to communication between people who own different cultural perceptions and have various cultural backgrounds. And language is a bridge for intercultural dialogue. Dodd (2006) held that intercultural communication is used to describe the influence of cultural diversity on communication outcomes between people with different cultural backgrounds. The contents and the way we communicate are affected by the different cultures. For example, when Chinese students are having a conversation in English, they are deeply influenced by traditional Chinese culture, and it is likely that they may think in Chinese mode, some negative transfer may occur in their English expressions, which is liable to cause misunderstandings. Therefore, people must raise their awareness of intercultural communication to have an effective exchange of ideas with native speakers.

In this section, classification of pragmatic failure will be discussed. The Co-operative Principle put forward by Grice (1975) and the Politeness Principle by Leech (1983) are introduced to serve as theoretical bases for further discussion of successful communication.

Cultural conflicts and communicative barriers often happen among people with different cultural psychology and social norms. And the communicative barriers are called pragmatic failures. Hu Wenzhong (1999) believed that cultural mistakes create awesome feelings between native speakers and English learners in China.

Pragmatic failure can be divided into pragmalinguistic failure and socio-pragmatic failures. Pragmalinguisitic failure refers to the error that people make when they fail to follow the pragmatic principle according to specific context of the situation when having a conversation with others. Unlike pragmalinguistic failures, socio-pragmatic failures refer to those misunderstandings made by people because of improper words or impolite way of talking with other people. Socio-pragmatic failure occurs when speakers do not have a good understanding of or even ignore others' social and cultural background. Therefore, if non-English majors do not learn English culture well, socio-pragmatic failure is likely to happen in intercultural communication.

There are some pragmatic principles that make an effective communication possible in a certain culture. The Co-operative Principle put forward by Grice (1975) and the Politeness Principle by Leech (1983) are the two basic ones.

Many speakers emphasize the principle of manner and they often lay stress on being simple while ignoring the evidence and honesty. American culture belongs to the Western culture, and Chinese culture to the Oriental one. As a result, speakers had their own values about which principles to highlight and which ones to ignore when applying the maxim to real conversation. Leech (1983) held that the cooperative principle proposed by Grice requires speakers that they should speak sincerely, and at the same time, they should provide adequate information. However, only CP has proved to be not enough. Therefore, the Politeness Principle is put forward as a complement to the Cooperative Principle. 
Gu Yueguo (1992) put forward five politeness maxims concerning Chinese culture, such as self-denigration maxim, address maxim, refinement maxim, and so on. For example, he thinks that refinement is using euphemistic language rather than direct expression when people are talking with others. And some words may sound impolite and can cause unpleasantness among people from various countries if spoken out directly without hesitation. As a result, using euphemistic expressions language functions as a good way to avoid being impolite. However, English and Chinese have their own cultural meanings of euphemistic expressions respectively. For instance, it is a tradition for the Chinese to let the old feel being respected by the youngsters, thus, the word "old" is not a taboo to be avoided. On the contrary, however, many English people hate the feeling of being considered as old, thus other expression like "senior" may be chosen to replace it.

\section{Typical Examples of Chinese Non-English Majors' Socio-pragmatic Failures in Intercultural Communication}

In this section, typical examples of socio-pragmatic failures on the part of the Chinese non-English majors will be addressed. These instances are concerned with four speech acts in intercultural communication, such as greeting, making a request, giving a compliment, and making apology.

\section{Greetings}

Greeting is attached great importance to in daily communication. It serves as an important link to emotional contact among people from different nations. Yi Lin (2011) thought that people with various cultural backgrounds might cause misunderstandings when greeting with each other, and pragmatic failure may occur in such a circumstance. In order to avoid pragmatic failure, people from different cultures should greet in a proper way.

For example, a Chinese student once greeted his former English classmate whom he had not met for nearly ten years, saying “Hi! You haven't changed a lot, have you?” The student meant to praise him for his classmate still looking so energetic and young, so he considered it proper to say so, while his foreign classmate felt unpleasant, thinking himself being offended. In fact, as far as English people are concerned, change is the only thing that is unchangeable in this changing world. And it is no good for people to keep the same when the world is changing and developing in every new day. This Chinese way to praise a foreigner is considered dishonest and insincere.

Besides, some Chinese students prefer to ask some private questions when meeting their foreign acquaintances. They might say "Hey, what are you going to do? Are you going to have a meal?” However, to some extent, such a question as what you are going to do is private in English culture, and this way of greeting will make the other misunderstand that he or she is invited to have a meal. In fact, this is just a common greeting in Chinese culture, similar to "How are you?”, not a real invitation to eat. Actually, in Western culture, the way to start a conversation is to talk about weather conditions.

Thus, it can be seen that in different countries or regions, people usually greet each other in different ways when they meet acquaintances. However, whatever the way people may choose, to make the expressions sound proper and polite is of great importance in intercultural communication.

\section{Requests}

As expected, the major request realization strategies: direct, conventionally indirect and non-conventionally indirect, which are commonly found in English are also available in Chinese. When making 
a request, the English people usually say in an indirectly way to show their politeness. However, Chinese non-English majors often behave in two extreme manners, over-directness or over-indirectness depending on different circumstances.

For instance, in China, an officer who has high social status can ask his employees to do something in a direct way, like "Mr. Liu, give me a copy of the information sheet". This kind of words may sound acceptable in Chinese culture, however, it is improper in English culture, because they regard it a kind of intrusion to their rights and freedom. And they usually say in this way, "Mr. Liu, could you please give me a copy of the information sheet? Thank you". A polite request should be made even though the speaker has an authority.

Another example, a Chinese student once asked her English teacher to help her with oral English. She asked, "Mr. Smith, I'd like to ask if you are busy these days?" "Yes, I've been working on my research recently”. On hearing this, she did not say anything then. Obviously, in this example, the Chinese student made a request in a Chinese way, and she did not make herself understood due to her over-indirectness. Consequently, she failed to express herself clearly, and consequently did not get her teacher's help as she did not make a proper request in intercultural communication between English and Chinese.

\section{Compliments}

People use compliments to show thanks, respect, good wishes, and encourage others, or to begin a conversation or sometimes avoid embarrassment properly. Compliments can be helpful in maintaining a normal relationship among people in daily communication. It is an ordinary social phenomenon existing in different cultures, reflecting people's communications at different levels. When giving a response to other's compliment, Chinese non-English majors tend to deny it, while English native speakers would like to accept it, feeling pleasant for being approved by others, and very often say "Thank you".

For example, an English girl once said to a Chinese girl, "You look beautiful in your dress". The Chinese girl responded, “No, I don’t think so. It’s just an ordinary one. And I have worn the dress for many years”. Obviously, this kind of response is unacceptable for English people, and they consider it harmful to the interpersonal relationship. The correct way is to acknowledge it and then say "Thank you".

For another instance, an American boy once said to a Chinese girl, "You are so pretty". The Chinese girl responded, "Na li, Na li (Where, where)" In fact, the girl's response is to show modesty since modesty is one of the important values in Chinese traditional culture. But in intercultural communication this kind of response may make others feel confused, and sometimes they have to continue to say that "Your face is pretty; your eyes are beautiful...”. This kind of misunderstanding occurs due to different values and customs between English and Chinese people. Chinese people are taught to be honest and modest when they are young, while Western people are taught to be strong and capable, only those who are capable can win and survive by showing your abilities.

\section{Apologies}

Apology, serving as a complement to a certain action, is helpful for rebuilding the harmonious relationship among the communicators. Therefore, the way to make and accept an apology in a proper way is an indispensable part of verbal communication; otherwise, misunderstanding will be quite likely to happen.

For example, a Chinese student asked his English friend to help him with her English writing at his home, his English friend agreed pleasantly. When his friend meant to leave his home, he said "Thank you very much. And I feel so sorry to have wasted so much of your precious time”. This leads to misunderstanding of 
communication, because the foreigner wondered why he said that kind of words, thinking it a waste of time for him to give a favor.

Another example, an American came to visit a Chinese family as a guest. The Chinese family invited him for dinner. Actually, the host had made a lot of Chinese dishes, but upon leaving he said, "I am sorry, for there are not many dishes. Please forgive me”. In fact, this made the American feel very confused. Why did he apologize? There are obviously many dishes. However, in Chinese culture, this is just a common modest statement upon leaving similar to saying "good bye".

So, this kind of misunderstanding can be avoided if the Chinese non-English majors learn more about English culture, then they can make more effective communications with native speakers.

\section{Causes of Chinese Non-English Majors' Socio-pragmatic Failures in Intercultural Communication}

Different economic backgrounds can lead to socio-pragmatic failures in English-Chinese intercultural communication. The development of history has witnessed the imbalance between the economic conditions of Western countries and China. For instance, questions about people's salary is considered to be private and impolite in Western people's eyes, but it is one of common daily topics in Chinese culture since China is still a developing country and people are very concerned about incomes. Talking about salary shows caring about the hearer. Thus, economic condition plays a significant role in communication between English and Chinese people. If non-English majors know little about the difference in economic background between English-speaking countries and China, it is likely to cause socio-pragmatic failure in intercultural communication.

Value, as the core of culture, indicates the judgment that focuses on religious belief, world view, virtue, and vice in people's behavior. Caring less about the taboos in a particular culture will exert a negative influence on people's communication. Different values are products of different cultures, and some normal topics in Chinese culture can make English people feel uncomfortable or even offensive. For example, a Chinese usually owes his/her success to the team or community that he/she belongs to, instead of thinking highly of himself/herself as English people do. The collective interests are generally put on priority than individual interests in Chinese culture.

Privacy is differently treated in Chinese and western cultures. For example, Western people are usually very sensitive about their privacy while Chinese people are less sensitive about the private affairs when talking with others. Some private issues in Westerner's eyes are not privacies in Chinese eyes like age.

As is known to all, Chinese culture is mainly about thinking in images. In other words, Chinese pay much attention to imaginative thinking, and it is a mental process where an idea is formed by metaphor, analogy, symbol, etc. The Chinese language attaches much importance to "ideas", "meanings", and "pictures" hidden in linguistic forms while logic is one of the major characteristics of Western thought. Correct structure of a sentence is firstly required in English but in Chinese, syntactical structure is secondary; semantic coherence is primary. Logical thinking involves analyzing, abstracting, reasoning, comparing, and generalizing. It should be rational, accurate, systematic, etc. This kind of thinking mode has profound effect on the structures of oral and written discourses in cross-cultural communication.

Customs mean the social habits that are formed as traditional maxims in human society. People in the society must follow the conventional customs consciously or unconsciously, and regard them as criteria during 
their communication with others. Both Chinese and English cultures have their distinctive customs owing to the development of their own history. The differences in customs function as one of the important causes for them to think and behave in a completely different way and hence may cause socio-pragmatic failures. Non-English majors do not learn the Western culture systematically, so they are less likely to have a good understanding of the English customs. Therefore, socio-pragmatic failure often occurs when they communicate with native English speakers.

Generally speaking, language transfer refers to the condition in which a learner of a second language prefers to choose a kind of expression corresponding to his/her mother tongue during communication with native speakers because he/she has been deeply affected by his/her native language. Depending on the different outcomes caused by language transfer in communication, it can be divided into negative pragmatic transfer and positive pragmatic transfer. Negative pragmatic transfer has been widely explored in interlanguage pragmatic research. To be more specific, socio-pragmatic failure occurs when speakers apply pragmatic principles blindly or mechanically during communication. Negative pragmatic transfer is closely linked to pragmatic failure. Chinese non-English majors should pay much attention to the differences between native language and target language, so that they can carry out a successful cross-cultural communication.

\section{Countermeasures to Reduce Chinese Non-English Majors' Socio-pragmatic Failure in Intercultural Communication}

\section{Cultivating the Student's Intercultural Awareness}

The diversity of cultures requires that Chinese non-English majors should have cultural awareness in order to have an effective communication with people from other countries. Liu Leilei (2018) thought that it is a common phenomenon that some Chinese non-native English majors speak English in an inappropriate way in cross-cultural communication due to the lack of knowledge of pragmatic functions of the target language. Elemam (2018) held that the aspect of social awareness of communication can be as important as language itself.

Fete (2017) thought that as globalization continues to deepen across the world, intercultural awareness has become increasingly important for every aspect of modern life. Hanvey (1987) held that intercultural awareness could be divided into three levels: awareness of superficial cultural traits; awareness of subtle cultural traits; and awareness of how another culture feels from the insider's perspective. It cannot be denied that people should try to understand and accept different behaviors from other cultures. Although it is impossible to understand and learn everything about other cultures totally, if people could increase their awareness of intercultural communication, many embarrassing things in communication can be avoided.

\section{Improving the Student's Intercultural Communicative Competence}

Intercultural communicative ability is a kind of competence to express respect to cultural differences, and it makes a person qualified for global citizenship. Shah-Gordon (2016) believed that it is critical that the institutions of higher education train leaders who are competent in cross-cultural communication practice, and are culturally sensitive to different perspectives. Wilson (2017) thought that learners may achieve proficiency in linguistic competence, but remain pragmatically underdeveloped and susceptible to pragmatic failure. It cannot be denied that the cultivation of intercultural competence is inseparable from the increase of intercultural awareness. 
Moreover, being familiar with different ways of people's life from various countries can be beneficial for individuals to make a solid foundation for the exchange of ideas. In fact, students should try to have face-to-face talk with English native speakers as much as possible, for instance, by going to English salons and joining in English Corner frequently, they can improve their intercultural communicative ability. Language learners will feel successful and build confidence if their desire of having an effective communication with foreigners in English is satisfied.

\section{Conclusion}

To conclude, this paper mainly explores Chinese non-English majors' socio-pragmatic failure in cross-cultural communication by analyzing some typical examples concerning the speech act of greeting, compliment, request, as well as apology-making. Some causes that lead to the pragmatic failure are also discussed, such as different economic backgrounds, values, thinking modes, and the negative pragmatic transfer. Furthermore, in order to help non-English majors have more effective communication with foreigners, some measures should be taken, such as increasing their intercultural communication awareness as well as improving their intercultural communicative competence by being engaged in more real cross-cultural communicative practice.

\section{References}

Arensberg, C., \& Niehoff, A. (1964). Introducing social change: A manual for Americans overseas. Chicago: Aldine.

Dodd, C. (2006). Dynamics of intercultural communication. Shanghai: Shanghai Foreign Language Education Press.

Elemam, S. M. (2018). Pragmatic competence and the challenge of speech expression and precision (MA thesis, University of Dayton).

Fete, E. M. (2017). Developing cosmopolitanism: Realizing the power of intercultural media and international experiences in a globalized world (Degree Doctor of Philosophy dissertation, Ohio State University).

Grice, P. (1975). Logic and conversation. In P. Cole and J. Morgan (Eds.), Syntax and semantics: Speech acts. New York: Academic Press.

Gu, Y. G. (1992). Politeness, pragmatics and culture. Waiyu Jiaoxue Yu Yanjiu, (4), 10-17.

Hanvey, R. (1987). Cross-cultural awareness. In L. Luce and E. Smith (Eds.), Toward internationalism. Cambridge: Newbury.

Hu, W. Z. (1999). Perspectives of intercultural communication. Beijing: Foreign Language Teaching and Research Press.

Kasper, G. (1992). Pragmatic transfer. Second Language Research, 8(3), 203-231.

Leech, G. (1983). Principles of pragmatics. London: Longman Press.

Liu, L.L. (2018). Appropriateness and pragmatic failure of English language use in English-Chinese intercultural communication. Journal of Hefei Polytechnic University (Social Science Edition), 32(1), 23-26.

Shah-Gordon, R. (2016). Intercultural competence development through civic engagement (Ph.D. dissertation, Antioch University).

Wilson, D. A. (2017). An investigation into the comprehensive development of L2 pragmatic competence in the EFL classroom: A case of advanced Serbian EFL learners (Ph.D. thesis, University of Surrey).

Yi, L. (2011). On pragmatic failure in intercultural communication. Journal of Sichuan College of Liberal Arts and Sciences, (3), 31-33. 